\title{
OSSIFICATION OF THE ANTERIOR LONGITUDINAL LIGAMENT: CLINICAL AND EMBRYOLOGICAL ASPECT
}

\author{
Parul Kaushal ${ }^{1}$, Ranjana Verma *2, Aritra Banerjee ${ }^{3}$, Raj D Mehra ${ }^{4}$ \\ ${ }^{1}$ Department of Anatomy, All India Institute of Medical Sciences, New Delhi, India. \\ ${ }^{* 2}$ Department of Anatomy, Government institute of medical sciences, Greater Noida, UP, India. \\ ${ }^{3}$ Department of Anatomy, All India Institute of Medical Sciences, Rishikesh, India. \\ ${ }^{4}$ Department of Anatomy, Hamdard Institute of Medical Sciences, Jamia Hamdard University, New \\ Delhi, India.
}

\section{ABSTRACT}

Normal anatomy of vertebral column is extremely vital for weight transmission as well as normal day to day activities. Osteogenic outgrowths and ossifications are commonly reported in literature; however, extensive ossification of the anterior longitudinal ligament $(A L L)$ is a rare finding. During routine undergraduate teaching in the Department of Anatomy, Hamdard Institute of Medical Sciences, New Delhi, we came across ossification in the ALL of an elderly male skeleton, extending from T9 to L2, with complete bridging between vertebrae T11 -T12 as well as L1- L2 and broken (possibly due to bone processing) in region between T9-T10, T10- T11, T12-L1. Ossification was extensive on the right side as compared to the left. Knowledge of such ossification will aid a surgeon during lateral transpsoas approach of vertebral column and prevent complications while performing surgeries in this region such as lordiosis restoration with ALL release and in placement of hyperlordotic cage etc.

KEY WORDS: Forestier's disease, diffuse idiopathic skeletal hyperostosis.

Address for Correspondence: Dr. Ranjana Verma, Professor \& Head, Department of Anatomy, Government institute of medical sciences, Greater Noida, UP, India. Mobile no: 7701807013 E-Mail:ranjanaverma318@gmail.com

Access this Article online Quick Response code

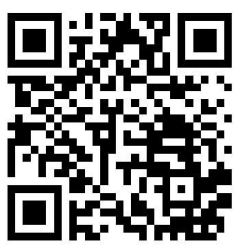

DOI: $10.16965 /$ ijar.2018.382

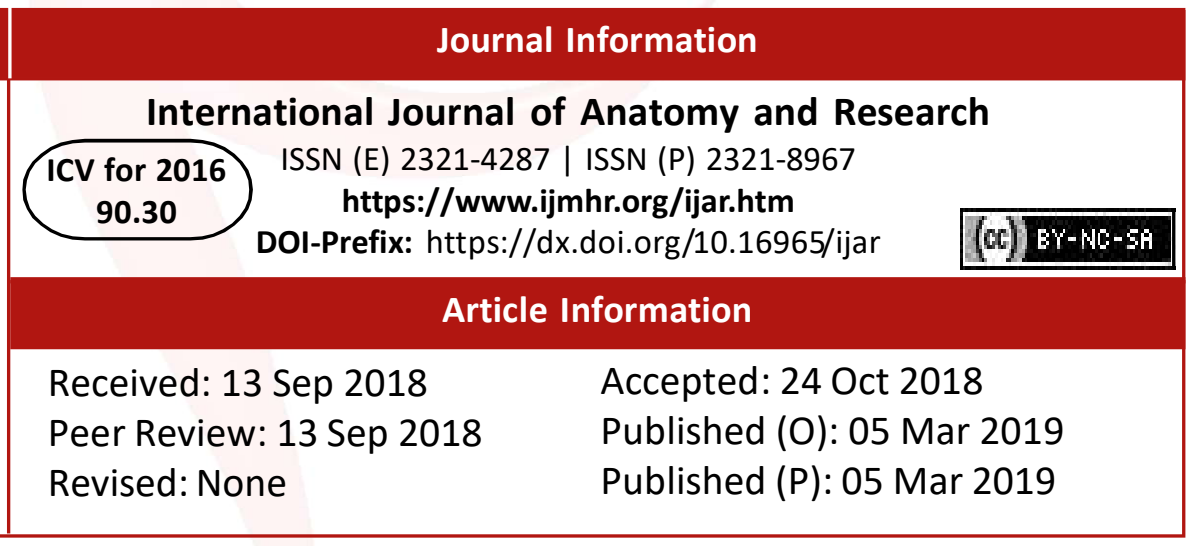

paediatric age groups as well $[2,3]$. It is usually asymptomatic; however, dyspnoea, dysphagia, spinal cord compression, and peripheral nerve entrapment have been associated with the disorder [4]. Most commonly ossified ligament in DISH is the ALL, which runs in front of the vertebral bodies (extending from the basilar part of the occipital bone up to the sacrum) supporting and stabilizing the vertebral column.

\section{CASE REPORT}

During undergraduate teaching in the Department of Anatomy, we came across ossification 
in the ALL in the lower thoracic and upper lumbar region of a vertebral column. The ossification appeared to continue from T9 to L2 with complete bridging between vertebrae T11-T12 as well as L1- L2 (*) and discontinuous (possibly due to bone processing) in region between T9-T10, T10- T11, T12-L1 ( $\rightarrow$ ). We also noted extensive regions of ossification on the right side of the vertebral body as compared to the left. A clear disc space along with normal zygoapophyseal joints were noted between two adjacent vertebral bodies. The intervertebral foramen and vertebral canal appeared normal (Figure 1A, B, C).

Fig. 1: Showing ossification in the anterior longitudinal ligament on anterior (A), left lateral (B) and right lateral (C) aspects of the lower thoracic and upper lumbar region of the vertebral column. Complete bridging $\left({ }^{*}\right)$ between vertebrae $\mathrm{T} 11$ and $\mathrm{L} 1$ as well as $\mathrm{L} 1$ and $\mathrm{L} 2$ and incomplete bridging between T9-T10, T10- T11, T12-L1 ( $\rightarrow$ ) was seen. Extensive ossification on the right side was noted as compared to the left side.

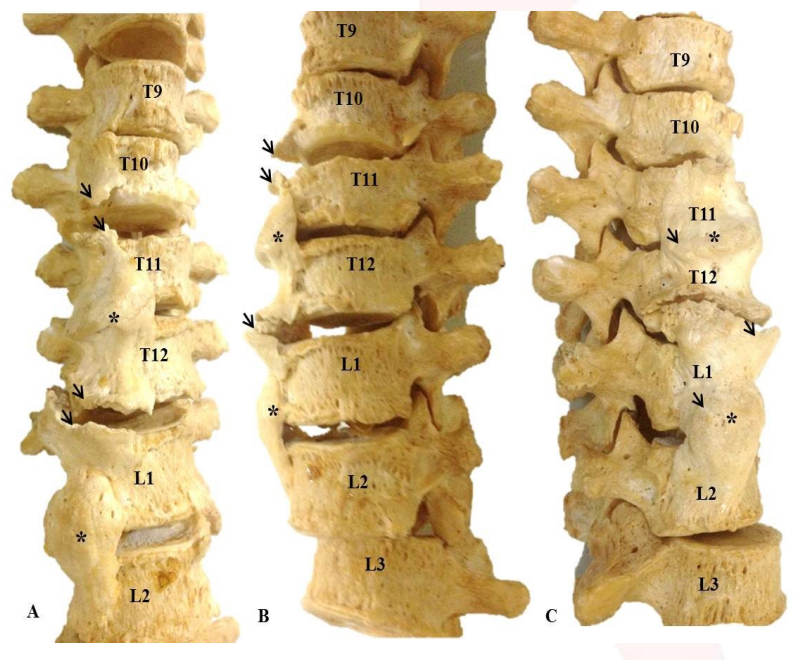

\section{DISCUSSION}

The features observed in the vertebral column pointed towards its classification as Forestier's disease corresponding to mixed type of ossification in ALL in the lower thoracic and upper lumbar region. One of the reasons of few clinical case reports of ossified ALL in thoracic and lumbar region is its asymptomatic presentation; however, this fact also highlights the necessity to be aware of such deviations, as it might prevent complications during surgeries involving the spine of this region.

DISH was the term coined by Resnick for cases presenting as extraspinal ossification in various ligaments associated with the vertebral column especially in the region of enthuses [1].

Ossification of ALL is most commonly seen in the thoracic region followed by cervical and lumbar regions [5]. Few authorities believe that ossification in the ligaments occurs to establish rigidity and limit the movement, however, such ossifications are most commonly reported in the thoracic region. This preferential manifestation in the thoracic region is contrary to the reasoning of its occurrence, as the thoracic region is one of the least mobile part of the vertebral column [6].

Another interesting fact described by Forestier includes its preferential occurrence on the side of the spine opposite to the aorta, based on his observation of ossification in ALL of left side in cases with dextrocardia as compared to right sided ossification in cases with normal left sided aorta. Although the exact mechanism of how aorta prevents the ligamentous ossification is not clear, however, some investigators have suggested the role of pulsatile action in preventing ossification [7]. This opens avenues for further research to identify markers expressed by aorta and its vicinity which prevent ossification. Since ossification is predominantly on right side it predisposes the right sided vasculature especially in the lower lumbar regions to be at greater risk during anterior column reconstruction using lateral transpsoas approach, as it involves sectioning of ALL while protecting the great vessels [8]. Thereby, making prior knowledge and identification of anatomical variants, as well as spinal deformities in the anterior aspect of vertebral column imperative for a surgeon exploring this region.

Mizuno et al based on the pattern of ossification, classified ALL ossification as continuous (complete ossification in ALL between adjacent vertebrae leading to their fusion), segmental (ossification in ALL in the region of body of vertebra and lacking in the region of the intervertebral disc) and mixed (being continuous in one part and segmental in other part). These investigators reported seven cases (elderly males) of Forestier's disease with two being segmental and mixed each and three being continuous. They noted ossification of ALL (in 
the cervical region as well as thoracic region) and posterior longitudinal ligament (PLL) (in the cervical and lumbar region); however, they did not observe any ossification in the ALL of lumbar region. Furthermore, they also documented neurological symptoms such as myelopathy (in six) and radiculopathy (in one) of the cases and correlated them to cervical stenosis resultant of the simultaneous ossification in ALL and PLL [9].

Mostly the ossification of ALL remains asymptomatic except in the cervical region where it may produce symptoms like dysphagia by compressing oesophagus, dyspnoea, stridor, cough by compressing upper airway and other complications like musculoskeletal and neurological symptoms with incidence of $20 \%$ to $30 \%$ in the elderly population [10].

Etiology of ossification of ALL remains unknown, however, its occurrence has been reported to be multifactorial with genetic, metabolic, endocrinologic, environmental and toxic factors playing a role in its pathogenesis. It has also been associated with malignancy and some metabolic disorders such as hyperinsulinemia with or without diabetes mellitus, obesity, hyperuricemia, dyslipidemia, hypertension, coronary artery disease [11].

Insulin like growth factor I (IGFI) induced stimulation of alkaline phosphatase and type II collagen synthesis has been reported as one of the mechanisms inducing ossification in the ALL [12].

Furthermore, appropriate vertebral blood supply is extremely crucial for maintenance of the normal vertebral anatomy as both hypervascularization and hypovascularization have been described to initiate the onset of ossification. ${ }^{[13,14]}$ Jin and co-workers based on their study on 15 midterm human foetuses postulated the existence of an ALL- bone interface containing osteoblasts between the posterior surface of the ALL and the anterior surface of the vertebral body [15]. These investigators hypothesized proliferation of these osteoblasts as the basis of ossification of the ALL in the elderly.

Although, our study is limited to the study of one vertebral column but it presents an interesting case, the knowledge of which will help prevent complications by a surgeon while performing surgeries in this region such as lumbar lordosis restoration with ALL release, placement of hyperlordotic cage as well as during laminectomy or laminoplasty.

\section{Conflicts of Interests: None}

\section{REFERENCES}

[1]. Resnick D, Shapiro RF, Wiesner KB, Niwayama G, Utsinger PD, Shaul SR. Diffuse idiopathic skeletal hyperostosis (DISH) (ankylosing hyperostosis of forester and rotes-querol). Semin Arthritis Rheum 1978;7:153-87.

[2]. Tsukamoto $Y$, Onitsuka H, Lee K. Radiologic aspects of diffuse idiopathic skeletal hyperostosis in the spine. AJR Am J Roentgenol 1977;129:913-8.

[3]. Coakley FV, Vive J. Childhood ossification of anterior longitudinal ligament of cervical spine. Clin Radiol 1995;50:115-16.

[4]. Mccafferty RR, Harrison MJ, Tamas LB, Larkins MV. Ossification of the anterior longitudinal ligament and Forestier's disease: an analysis of seven cases. J Neurosurg 1995;83:13-17.

[5]. Zaman MU, Fatima N, Sajjad Z, Zaman U, Zaman A, Tahseen R. Pseudo thyroid lobe: A diagnostic conundrum caused by ossified anterior longitudinal ligament on bone scan. IJNM 2005;30:78-79.

[6]. Mccafferty RR, Harrison MJ. Ossification of anterior longitudinal ligament and forestiers disease:an analysis of seven cases. J Neurosurg 1991;85:52425.

[7]. Forestier J, Lagier R. Ankylosing hyperostosis of the spine. Clin Orthop 1951;74:65-83.

[8]. Marchi L, Pimenta L, Oliveira L, Fortti F, Amaral R, Abdala N. Distance between Great Vessels and the Lumbar Spine: MRI Study for Anterior Longitudinal Ligament Release Through a Lateral Approach. J Neurol Surg 2016. DOI 10.1055/s-0036-1592144.

[9]. Mizuno J, Nakagawa H, Song J. Symptomatic ossification of the anterior longitudinal ligament with stenosis of the cervical spine. JBJS 2005;87b(10):1375-9.

[10]. Granville L, Musson N, Altman R, Silverman M. Anterior cervical osteophytes as a cause of pharyngeal stage dysphagia. J Am Geriatr Soc 1998;46:1003-7.

[11]. Kiss C, Szilagyi M, Paksy A, Poor G. Risk factors for diffuse idiopathoic skeletal hyperostosis: a casecontrol. Rheumatol 2001;41:27-30.

[12]. Denko CW, Boja B, Moskowitz RW. Growth promoting peptides in osteoarthritis and diffuse idiopathic skeletal hyperostosis- insulin, insulin like growth factor I, growth hormone. J Rheumatol 1994;21:1725-30.

[13]. Khalifa MC, Amr F, Fouly SE, Aouf M. Ossification of the anterior longitudinal ligament of the spine as a cause of dysphagia. J Laryngol Otol 1981;95:52728. 
[14]. ElMiedany YM, Wassif G, ElBaddini M. Diffuse idiopathic skeletal hyperostosis (DISH): is it of vascular aetiology? Clin Exp Rheumatol 2000;18:13-200.

[15]. Jin WJ, Song KJ, Lee NH, Nakamura T, Fujimiya M, Murakami G, Cho BH. Contribution of the anterior longitudinal ligament to ossification and growth of the vertebral body: an immunohistochemical study using the human fetal lumbar vertebrae. Surg Radiol Anat 2001;33:11-18.

How to cite this article:

Parul Kaushal, Ranjana Verma, Aritra Banerjee, Raj D Mehra. OSSIFICATION OF THE ANTERIOR LONGITUDINAL LIGAMENT: CLINICAL AND EMBRYOLOGICAL ASPECT. Int J Anat Res 2019;7(1.3):6326-6329. DOI: 10.16965/ijar.2018.382 